\title{
Bridges across the Racial Digital Divide: Residen- tial Ecology of Internet Use
}

\author{
Eric Fong \\ University of Toronto \\ fong@chass.utoronto.ca \\ Xingshan Cao \\ University of Toronto \\ xs.cao@utoronto.ca
}

\begin{abstract}
Our paper extends the study of residential ecology to understand social changes, specifically the adoption of Internet use. We suggest that the residential ecology of the metropolitan area, in addition to household socioeconomic factors, should be considered in understanding Internet use. The centripetal dimension of residential ecology, represented by residential isolation and the spatial concentration of the poor, and the centrifugal dimension of residential ecology, reflected by residential interaction of groups, are important to understanding the digital divide among racial groups. Based on the August 2000 Current Population Survey Computer and Internet Use Supplement, our results demonstrate that residential ecology is important to understanding the digital divide of groups, especially groups with low rates of Internet use, i.e., blacks and Hispanics. Implications are discussed.
\end{abstract}

Keywords: residential ecology, internet use, ethnic groups, metropolitan regions

\section{Résumé}

Notre article a étendu l'étude de l'écologie résidentielle dans le but de comprendre les changements sociaux; et spécialement l'adoption de l'utilisation d'internet. Nous suggérons que l'écologie résidentielle de la région métropolitaine, en outre des facteurs socioéconomiques des ménages, devrait être prise en compte pour comprendre l'utilisation d'internet. Nous avançons que la dimension centripète de l'écologie résidentielle, tel que représentée par l'isolation résidentielle et la concentration spatiale des pauvres, ainsi que la dimension centrifuge de l'écologie, tel que reflétée par l'interaction résidentielle entre les groupes, sont des facteurs importants pour comprendre la division numérique entre les groupes; et spécialement les groupes qui ont les taux d'utilisation les moins élevés, c'est-à-dire les noirs et les hispaniques. Les implications de ces faits sont discutées.

Mots-clés: Écologie résidentielle, utilisation d'internet, groupes raciaux, région métropolitaine 


\section{Introduction}

Racial and ethnic residential patterns are one of the most important avenues for exploring group relations. Most studies on the topic have focused on the patterns, formation, and consequences of racial and ethnic residential patterns (Fischer et al., 2004; Logan et al., 2004; Wilkes and Iceland, 2004; Iceland et al., 2002; Alba et al., 1995; White et al., 1993; Massey and Fong, 1990; Massey and Denton, 1987). However, to our knowledge, only a few studies extend this basic understanding of racial and ethnic residential patterns to include their effects on the adoption of technology among groups (Mossberger et al., 2006). The study of Internet use in particular is limited.

With the drastic rise in Internet use in recent decades, many studies have been devoted to understanding patterns of Internet use among different racial and ethnic groups. These studies show substantial group variation (Mossberger et al., 2003; Servon, 2002; Dryburgh, 2001; Spooner and Rainie, 2004; 2001; Wilson, 1999). Blacks and Hispanics have the lowest rates of Internet use, while whites have the highest rate (Economic and Statistics Administration and the National Telecommunications and Information Administration, 2002; Spooner and Rainie, 2004). To explain these differences, research has focused on the differential human capital of individuals and households in various groups (Servon, 2002; Nie and Erbring, 2000; Kominski and Newburger, 1999). Little theoretical or empirical attention has been paid to the link between Internet use and residential ecology.

In this study, we explore how city residential ecology affects the adoption of Internet use among different racial and ethnic groups in major American cities. Residential ecology here refers to the residential patterns of different racial and ethnic groups in metropolitan areas. Drawing from the literature on neighbourhood effects, we argue that residential ecology still plays a relevant and important role in the adoption of technology and in explaining racial differences in Internet use. To achieve conceptual clarity, we differentiate residential ecology into centripetal and centrifugal dimensions, as suggested by Massey's (1985) earlier work. We use the 2000 Current Population Survey Computer and Internet Use Supplement, which provides information on Internet use, to carry out a series of hierarchical linear models to determine the direct effects of the residential ecology of metropolitan areas on the Internet use of the groups living there. We also explore how the residential ecology of metropolitan areas is related to household socioeconomic standing, which in turn affects Internet use among groups.

We contribute to the existing literature in the following ways. First, we clarify the concept of residential ecology by differentiating the unique roles of the two dimensions of residential ecology cited above and then discussing their possible effects on Internet use. Second, we extend the literature on race and ethnic residential segregation patterns, moving from an understanding of various social and demographic behaviours to an understanding of the adoption of technology, specifically Internet 
use. Third, we consider the multiethnic context of residential ecology and discuss its relationship with Internet use.

\section{Literature Review}

In recent years, studies by Massey and Denton (1993) and Wilson (1987) have forcefully demonstrated the importance of residential ecology in understanding individuals' and groups' life chances. These studies, in turn, have triggered a whole array of studies on the relationship of the residential ecology of metropolitan areas with various economic, social, and demographic patterns among groups, including crime and deviance (Sampson et al., 1999) and other group demographic patterns, such as fertility (Haveman et al., 1997), marriage (Steir and Tienda, 2001), and mortality patterns (Polednak, 1997). They have provided considerable insight into how residential ecology is related to differences in social, economic, and demographic patterns among groups.

However, most of these studies focus only on the effects of one aspect of residential ecology, namely, either residential isolation or residential interaction. As Massey noted in his earlier work (1985), residential ecology has two dimensions: the centripetal and the centrifugal. He suggested that the centripetal dimension of residential ecology represents factors that draw group members together and manifests in the residential isolation levels of groups, while the centrifugal dimension consists of factors that push groups out from a location and is reflected in the residential interaction levels of groups. Thus, research focusing on one dimension may reveal only part of the phenomenon. Hawley (1986) approached the issue from a more abstract level, yet arrived at a similar understanding. He argued that both centripetal and centrifugal tendencies are important in disentangling the relationships among units and their changes in an ecosystem: more specifically, these tendencies can have different implications for different units in the ecosystem with respect to both functions and resources. Therefore, it is clear that differentiating the centripetal and centrifugal dimensions of residential ecology will provide a more detailed and comprehensive picture of the relationship between residential ecology and Internet use.

In the following discussion, we draw upon work from the literature on residential patterns to discuss how Internet use is affected by the centripetal dimension of residential ecology, represented by residential isolation levels, and the centrifugal dimension of residential ecology, reflected in residential interaction levels.

\section{Residential Isolation: Centripetal Dimension of Residential Ecology}

Recent studies on ethnic communities show a growing caution in applying the traditional understanding of the consequences of residential isolation. They indicate that 
it is important to be aware of the cause of residential isolation, because it can have considerable implications for the consequences of individual behaviour (Lieberson, 1982; Clark, 1986). A group who chooses to live in close proximity to its own ethnic members for various reasons, especially recent immigrant groups, such as Asians and Hispanics, can also choose to interact with other groups in different contexts. Consequently, such groups may not necessarily experience social isolation. However, groups clustering in neighbourhoods, largely as a consequence of housing discrimination, may reflect broader discrimination in other aspects of their lives (Massey and Denton, 1993). Thus, in a discriminatory environment, these groups may develop reactive behaviour against the context in order to defend their own interests and positions (Wilson, 1996; Ogbu, 1992; Anderson, 1990). In the main, they develop behaviour to steer around the hurdles. Such group reactive behaviours can have a significant impact on ethnic community development (Portes and Sensennbrenner, 1993) and the people residing there.

Since most research confirms that blacks experience residential isolation largely due to housing discrimination, we expect that blacks in metropolitan areas with high levels of residential isolation will be more likely to develop reactive behaviour in response to possible social isolation stemming from their residential isolation. In fact, blacks living in these metropolitan areas use various ways to obtain information and to maintain their networks, including the Internet, that go beyond their constrained social and physical environment (Pew Internet and American Life Project, 2000). It seems that Internet access can minimize the geographic constraints of developing social ties (Wellman et al., 1996) and expand social capital beyond its own location (Lin, 2001). Recent studies echo this reasoning and have found that blacks are more likely than other groups to use the Internet to search for job, housing, and health care information, and to acquire new knowledge (Pew Internet and American Life Project, 2000).

To fully understand black residential isolation, we explicitly note two major findings from two lines of study. First, recent studies have pointed out that a large proportion, about half of employed blacks, have middle-class jobs. Further, these middle-class blacks disproportionately live in black majority neighbourhoods (Pattillo-McCoy, 1999). Therefore, black residential isolation in metropolitan areas is not related only to poor black neighbourhoods. Second, research has documented that blacks with higher levels of education are more likely to use the Internet (Spooner and Rainie, 2004; Alvarez, 2003; Hoffman and Novak, 1998). Using the 2000 and 2002 General Social Survey, Alvarez (2003) documented that blacks who have completed college have a high rate of Internet use, even higher than whites who have completed college. These findings are echoed by PattilloMcCoy's (1999:103) ethnographic study of middle-class black neighbourhoods on the South side of Chicago, which showed that youth in that area use Internet access and familiarity with technology as resources for overcoming their segregated environment. Taken together, these studies indicate that blacks, especially those with 
a higher level of education, who reside in metropolitan areas with higher levels of residential isolation, are more likely to use the Internet.

\section{Spatial Concentration of the Poor: A Special Case of Residential Centripetal Ecology}

Massey (1990) clearly established that, given the considerable number of poor urban households, a simple increase in the residential isolation of poor households can increase the spatial concentration of the poor. This finding has received a great deal of attention, because the spatial concentration of poverty is accompanied by an array of social and economic changes that have detrimental implications for those residing there (Massey, 1990; Wilson, 1987; Massey and Shibuya, 1995). The resulting social pathology, which Wilson (1987) called the "concentration effect," typically includes high rates of crime, unemployment, and poor housing conditions.

Sampson and Wilson (1995) later argued that such concentration effects result from the combined conditions of structural social disorganization and cultural social isolation. Here, social disorganization refers to the "inability of a community structure to realize the common values of its residents and maintain effective social controls" (Sampson and Wilson, 1995:45), while cultural social isolation suggests a lack of interaction with the mainstream society, which may lead to the development of a community subculture and detachment from mainstream expectations. Sampson and Wilson concluded that the spatial concentration of poverty creates intense disadvantages for residents by weakening their social control and constraining their interaction.

Research into the effects of high spatial concentration of poverty provides important insight into group inequalities in social and economic well-being. To date, however, the discussion of how it affects the adoption of technology has been limited (Mueller and Schement, 1996). Drawing from the understanding of social disorganization with regard to the spatial concentration of poverty, we suggest that in a group with a larger percentage of poor and a higher spatial concentration of poverty, a larger percentage of members will not have the luxury of exploring new technologies. Their major concerns will be economic survival and maintaining decency in their neighbourhoods (Wilson, 1996; Anderson, 1990). At the same time, the discussion of cultural social isolation in relation to the spatial concentration of poverty implies that in metropolitan areas with a larger percentage of poor from a group that experiences a higher level of residential isolation, the group in question will have fewer interaction opportunities with those, even from their own group, who have resources (Wilson, 1987). Consequently, they will be deprived of role models (Massey and Denton, 1993; Wilson, 1996) and mainstream social networks (Sampson and 
Wilson, 1995). These negative network externalities may affect their awareness of the importance of Internet use in various aspects of their daily activities. Therefore, those who are living in metropolitan areas with higher levels of spatial concentration of poverty and a higher percentage of poor from their own group are less likely to use the Internet.

\section{Residential Interaction with Other Groups: Centrifugal Dimen- sion of Residential Ecology}

The centrifugal dimension of residential ecology refers to the spatial interaction between groups. It is related to the extent to which a group shares neighbourhoods with other groups in a metropolitan area. One can obtain the level of residential interaction from the levels of residential isolation if only two groups exist in the metropolitan area. As metropolitan areas are increasingly multiethnic, however, the simple two-group scenario can rarely be applied. Nevertheless, the measure of residential interaction can still provide unique information about interaction between two specific groups in a multiethnic context.

The contact hypothesis suggests that spatial arrangements allow groups to learn from each other, and reduce differences among groups (Powers and Ellison, 1995; Sigelman and Welch, 1993). Sharing neighbourhoods with other groups increases opportunities for interaction with these groups in an informal setting. Information across groups will be shared, intergroup friendships will be developed, social networks will be extended, and the norms and values of the wider society will be learnt (Welch et al., 2001). Although all groups will benefit from sharing neighbourhoods with other groups, it is especially important for minority groups with limited resources.

Following the same argument, we expect that sharing neighbourhoods with other groups, especially with those who have higher rates of adopting technology, will facilitate information sharing about new technology and will increase exposure to new technology in informal communication and social activities, especially among groups who normally have lower rates of adopting technology. Using Castells' (2000) term, such interaction within a neighbourhood indicates a "space of flow." Given this, we expect that Internet use by groups, especially blacks and Hispanics who have lower rates of Internet use, will be greater in metropolitan areas with higher levels of residential interaction.

Drawing from the above discussion, we suggest the following hypotheses:

1. Blacks, especially those with a higher level of education, who reside in metropolitan areas with higher levels of residential isolation are more likely to use the Internet.

2. Those who live in metropolitan areas with higher levels of spatial concentration of poverty and a higher percentage of poor from their own group are less likely to use the Internet. 
3. Internet use by blacks and Hispanics will be greater in metropolitan areas with higher levels of residential interaction.

\section{Data and Methods}

\section{Data}

We are interested in how the residential ecology of metropolitan areas affects individual Internet use. Information about individual Internet use was obtained from the August 2000 Current Population Survey (CPS) Computer and Internet Use Supplement. Information about the residential ecology of metropolitan areas was drawn from two other sources. We obtained data on segregation indexes and the percentage of poor in each racial and ethnic group in metropolitan areas from the website of the Mumford Centre of the University of Albany. Their segregation indexes were calculated from the 2000 census tract data. The second set of data, which contains the occupational distribution of metropolitan statistical areas (MSAs), was obtained from the occupational statistics of the US Bureau of Labor Statistics (BLS). We controlled for occupational distribution in the metropolitan areas to avoid possible occupational effects on Internet use. CPS covers respondents in 242 MSAs, and BLS includes information on 280 MSAs. When both files are combined, only 173 MSAs contain information from both data sets. Therefore, our final data set includes respondents residing in these MSAs. To get a complete picture, we also controlled individual socioeconomic and demographic information, which was obtained from the corresponding August Current Population Survey.

The unit of analysis is the household. Samples are restricted to household heads who are of working age, between 18 and 65. Instead of including all households, we included only household heads of working age because their use of the Internet can have considerable influence on their own well-being as well as that of their household members. To include household heads beyond 65 may make the interpretation of results more difficult. The daily routine and the incentive to use the Internet can be quite different for those who are of working age and those who are retired (Cutler et al., 2003). About 14,654 cases are included in the final analysis. We included nonHispanic whites, non-Hispanic blacks, Hispanics, and non-Hispanic Asians. Hereafter, however, we refer to non-Hispanic whites as whites, non-Hispanic blacks as blacks, and non-Hispanic Asians as Asians.

The dependent variable is current household use of the Internet at home. This variable is based on the following two questions: (1) "Earlier you said that you have both a computer and WebTV. Does anyone in this household use either one to connect to the Internet?" (HESIU2); and (2) "Does anyone in this household use the Internet from home?" (HESIU3A). A "yes" answer to either question is treated as using the Internet at home. Hereafter, we refer to the dependent variable, "household current use of Internet at home," as "Internet use." We are interested in understanding 
whether household heads have adopted new technology at home rather than at other locations. We focus on Internet use at home because people spend most of their time using the Internet at work or school for activities related to job or school. Internet use at home is more likely to reflect their use of the Internet for personal purposes, such as recreational Internet surfing, updating knowledge, or obtaining specific information - activities which can have considerable impact on their social activities, and may even have economic and political consequences.

To capture the centripetal and centrifugal dimensions of residential ecology in metropolitan areas, we include two variables. The first variable is the isolation index. It refers to the probabilities that a person is residing in a neighbourhood with someone from the same group. In other words, it measures the centripetal dimension of the residential ecology of metropolitan areas. The index was first suggested by Bell (1954), and later popularized by Lieberson (1980). It is expressed as

$$
P_{\mathrm{xx}}^{*}=\sum\left(\frac{X_{i}}{X}\right)\left(\frac{X_{i}}{T_{i}}\right)
$$

where $\mathrm{X}_{\mathrm{i}}$ is the population of group $\mathrm{X}$ in census tract $\mathrm{i}$, and $\mathrm{X}$ is the total population of group $\mathrm{X}$ in the city, and $\mathrm{T}_{\mathrm{i}}$ is the total population in census tract $\mathrm{i}$. A higher value of the isolation index suggests a higher residential isolation level of the group in the metropolitan area.

The second variable is the interaction index, which measures the centrifugal dimension of residential ecology, the level of potential contact between groups within the census tract. For residential interaction between groups, the interaction index is

$$
P_{\mathrm{xx}}^{*}=\sum\left(\frac{X_{i}}{X}\right)\left(\frac{Y_{i}}{T_{i}}\right)
$$

where $\mathrm{Y}_{\mathrm{i}}$ is the population of group $\mathrm{Y}$ in the census tract. The interaction index score can be obtained from the isolation index if there are only two groups in the metropolitan area. The measure suggests the probabilities of a person from group $\mathrm{X}$ residing in a neighbourhood with someone from group Y. As with the previous index, the higher the value of the interaction index, the higher the residential interaction level between the two groups in the metropolitan area.

We also include a variable to capture the spatial concentration of poverty in the metropolitan area. It is an interaction term of the isolation index and the percentage of a group living in poverty in the metropolitan area, an approach which follows the study of Massey and Egger (1990) on the effect of residential segregation on the concentration of poverty. Massey and Egger argued that although the economic composition of a group affects various social behaviours, the effect is alleviated with a higher level of residential segregation. We therefore expect that Internet use can be affected by the interaction effect of the percentage of poor within a group and the residential isolation level of the group. The use of new technology is less likely to permeate a spatially isolated group with a large percentage of members who are poor. 
We include two variables to measure the salient aspects of a city's occupational distribution that are pertinent to the adoption of technology. We controlled for the percentage of management and blue-collar jobs in the city. Managerial staff are more likely to use the Internet in relation to their jobs, and find it important to maintain Internet access at home, while individuals in manufacturing occupations whose jobs less likely involve Internet use are less likely to use the Internet at home. Therefore, cities with a higher percentage of management are more likely to have a higher rate of Internet use at home. Finally, we controlled for suburban residential location in order to find possible ecological differences, such as low density in housing, which may encourage residents in suburban areas to maintain contact through the Internet (Hampton and Wellman 2003).

To capture the possible effects of the socioeconomic background of the household, we include the educational level of the household head, household income level, and the immigration status of the household. Educational levels were categorized as less than high school, high school completion, some college, and university completion. We expect household heads with higher levels of education to be more likely to realize the importance of Internet use (Fong et al., 2001). They are more likely to adopt the new technology at home. Household income was divided into five categories: $\$ 19,999$ or less, $\$ 20,000-\$ 39,999, \$ 40,000-\$ 59,999, \$ 60,000-\$ 74,999$, and $\$ 75,000$ or above. From previous studies, we expect households with more financial resources to be more likely to try new technologies (Fong et al., 2001). Finally, an immigrant household is defined as one in which at least one spouse is an immigrant. We expect immigrant households to be more likely to use the Internet than most native-born persons: they are more likely to use the Internet to keep in touch with their home countries.

\section{Methods}

To assess appropriately how residential ecology factors affect Internet use when individual factors are included in the models, we employed a Hierarchical Linear Model (HLM), running three models for each racial and ethnic group.

First, we ran an unconditional model, an analogue to a one-way ANOVA model with random effect (Raudenbush and Bryk 2002). The results inform us of the average probability of Internet use for each group and metropolitan level random effect. The results determine whether or not, based on the preliminary findings, it is worthwhile to pursue the effects of the residential ecology of metropolitan areas on Internet use.

The second model involves the random-intercept model. The intercept of the model is a function of the residential ecology of metropolitan areas and other metropolitan characteristics. All household characteristics are treated as fixed effects. The random-intercept model helps to disentangle the effects of the residential ecology of metropolitan areas on Internet use, controlling for other metropolitan and household characteristics. 
The third model also is a full HLM model. In this model, in addition to variables included in the previous models, cross-level interactions between the residential ecology of metropolitan areas and household characteristics are included. This model helps to disentangle the direct effects of the residential ecology of metropolitan areas and the cross-level interaction effects of the residential ecology of metropolitan areas and household characteristics on Internet use.

\section{Discussion}

Table 1 shows the descriptive statistics of all variables included in the analysis. The results clearly show that white and Asian households have a considerably higher percentage of Internet use at home than do black and Hispanic families. Both white and Asian families have more than 50\% current Internet use at home, compared to only about $25 \%$ of black and Hispanic families. Thus, a clear digital divide along racial lines is documented.

Most studies have suggested that such a divide is related to socioeconomic differentials among groups. The descriptive data do indeed reflect such patterns in most of the cities in the analysis. Both black and Hispanic households have higher percentages of income lower than $\$ 40,000$ and of household heads with high school completion or less. On average, about $62 \%$ of black and $64 \%$ of Hispanic households have income less than $\$ 40,000$. In contrast, only about $41 \%$ of Asian and $36 \%$ of white households have the same level of income. Similarly, about $47 \%$ of black and $61 \%$ of Hispanic household heads have only high school completion or less, compared to $28 \%$ of Asians and $32 \%$ of whites.

The results also reveal considerable differences in the residential ecology where these groups reside. While most blacks and Hispanics reside in metropolitan areas with similar levels of residential isolation, these levels are higher than in the metropolitan areas where most Asians reside. The average residential isolation level of metropolitan areas where blacks and Hispanics reside is 47.6 and 42.5 respectively, while it is 28.6 for Asians.

Levels of residential interaction in the metropolitan areas where these groups reside are varied as well. Asians experience a higher level of residential interaction with whites than do blacks or Hispanics. At the same time, levels of residential interaction with blacks are higher for Hispanics than for Asians or whites. In addition, there are variations within groups. In fact, the standard deviation particularly suggests that there are considerable differences in levels of residential interaction within groups. Given the differences in residential ecology where these groups reside and the variation within each group, it is important to explore how residential ecology in addition to household characteristics affects the Internet use of different groups. 
Table 1. Descriptive Statistics of Household and Metropolitan Characteristics of Whites, Blacks, Hispanics, and Asians in Selected 173 MSAs, 2000

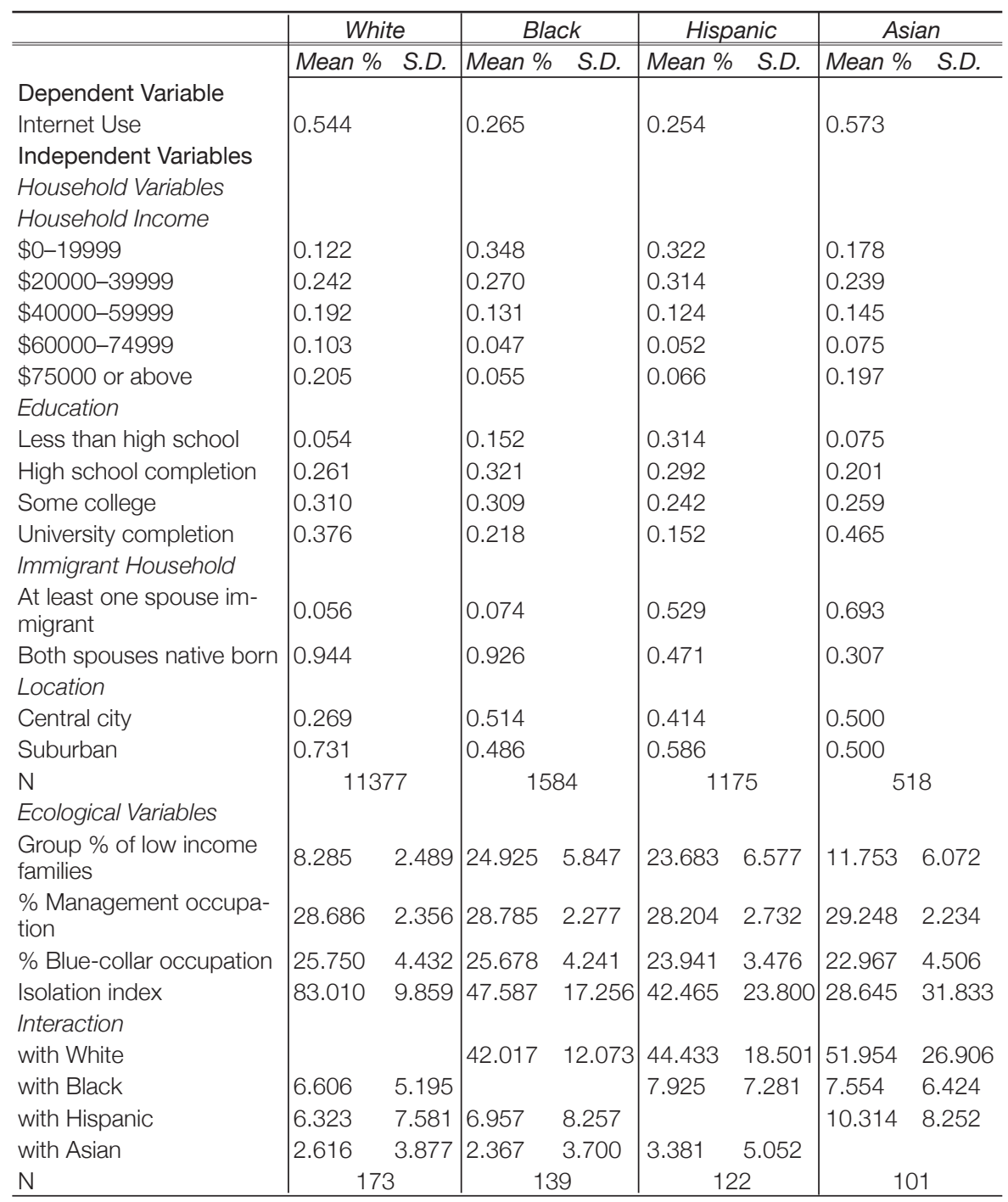

Table 2 shows the results for Internet use using a one-way ANOVA model with random effect. The fixed effect coefficient shows the average probability of Internet use for the group. While the random effects suggest variation among metropolitan areas, the fixed effect coefficients suggest log-odds of using the Internet at home when there is no variation among metropolitan areas. For blacks and Hispanics, the $\log$-odds of the fixed effects of Internet use are -1.082 and -1.043 respectively, while 
Table 2. Coefficients of Unconditional Model on Internet Use at Home of Whites, Black, Hispanics, and Asians, in selected MSAs 2000

\begin{tabular}{|c|c|c|c|c|c|c|c|}
\hline & \multicolumn{2}{|c|}{ Whites } & \multicolumn{2}{|c|}{ Blacks } & \multicolumn{2}{|c|}{ Hispanics } & \multirow{2}{*}{$\begin{array}{c}\text { Asians } \\
\text { Coefficient S.E. }\end{array}$} \\
\hline & Coefficient & S.E. & Coefficient & S.E. & Coefficient & S.E. & \\
\hline Fixed effect & $0.163^{\star \star \star}$ & 0.029 & $-1.082^{\star \star \star}$ & 0.072 & $-1.043^{\star \star \star}$ & 0.086 & $0.361^{\star * *}$ \\
\hline Random effect & $0.062^{\star \star \star}$ & & $0.120^{\star \star \star}$ & & $0.156^{\star \star \star}$ & & 0.100 \\
\hline
\end{tabular}

Note: ${ }^{\star \star \star} \mathrm{p}<0.01 ;{ }^{* \star} \mathrm{p}<0.05 ;{ }^{\star} \mathrm{p}<0.1$

the log-odds are 0.163 for whites and 0.361 for Asians. The odds for blacks, Hispanics, whites, and Asians respectively are $0.339(\exp (-1.082)), 0.352(\exp (-1.043))$, $1.178(\exp (0.163))$, and $1.435(\exp (0.361))$. Blacks and Hispanics have lower odds of using the Internet at home than do whites and Asians when there is no variation among metropolitan areas.

The random effects of the one-way ANOVA model show the variation in Internet use among metropolitan areas. Random effects of all models are significant, except for Asians. The results strongly suggest that there are substantial variations among metropolitan areas in rates of Internet use for all groups, except Asians.

\section{Random-Intercept Models}

In this section, we explore whether residential ecology helps to explain a group's Internet use, controlling for household factors, and helps us to understand the relationship and relative importance of residential ecology to a group's Internet use. To answer these questions, we ran the random-intercept model, which explores how residential ecology is related to Internet use, controlling for other metropolitan factors and household characteristics. The top panel of Table 3 presents the coefficients of the intercept that "decomposes" into effects of residential ecology and other city characteristics, while the bottom panel reveals household characteristics. Our discussion will focus on the effects of city ecological factors.

Although the HLM program can provide three different estimates based on three distinctive links, we chose to report the results of the population-average model with a logit link. The population-average model with a logit link gives the nonlinear increment of the estimated probability of Internet use when the unit changes in any independent variable. This practice avoids obtaining "negative" probabilities (Raudenbush and Bryk, 2002). We report the estimated log-odds and the robust standard error in Table 3.

The odds ratio of Internet use by whites only marginally relates to various indexes measuring residential ecology and other metropolitan characteristics. Among other metropolitan factors, only the percentage of blue-collar workers in metropol- 
Table 3. Coefficients of Random Intercept Model on Internet Use at Home among Whites, Black, Hispanics, and Asians, in selected 173 MSAs, 2000

\begin{tabular}{|c|c|c|c|c|c|c|c|c|}
\hline \multirow[b]{3}{*}{ Ecological Factors (Fixed Effects) } & \multicolumn{2}{|c|}{ Whites } & \multicolumn{2}{|c|}{ Blacks } & \multicolumn{2}{|c|}{ Hispanics } & \multicolumn{2}{|c|}{ Asians } \\
\hline & Coefficient & S.E. & Coefficient & S.E. & Coefficient & S.E. & Coefficient & S.E. \\
\hline & $0.165^{\star \star \star}$ & 0,031 & $-1414^{\star * *}$ & 0.105 & $-1329^{\star * *}$ & 0133 & $0428^{\star \star \star \star}$ & 0131 \\
\hline $\begin{array}{l}\text { Group percentage of low- } \\
\text { income families }\end{array}$ & -0.051 & 0.038 & -0.046 & 0.032 & -0.047 & 0.034 & -0.051 & 0.034 \\
\hline $\begin{array}{l}\text { Percentage of management } \\
\text { occupation }\end{array}$ & 0.012 & 0.013 & 0.023 & 0.036 & $0.084^{*}$ & 0.051 & -0.094 & 0.066 \\
\hline $\begin{array}{l}\text { Percentage of blue-collar oc- } \\
\text { cupation }\end{array}$ & $-0.033^{\star \star \star}$ & 0.007 & -0.022 & 0.022 & 0.001 & 0.028 & $-0.139^{\star \star \star}$ & 0.041 \\
\hline Isolation index & -0.002 & 0.033 & $0.118^{\star \star}$ & 0.052 & -0.059 & 0.055 & -0.019 & 0.058 \\
\hline Interaction index with whites & - & - & $0.122^{\star \star}$ & 0.061 & -0.044 & 0.060 & 0.018 & 0.059 \\
\hline Interaction index with blacks & -0.005 & 0.033 & - & - & -0.017 & 0.056 & 0.022 & 0.059 \\
\hline Interaction index with Hispanics & 0.011 & 0.035 & $0.114^{\star *}$ & 0.057 & - & - & -0.020 & 0.059 \\
\hline Interaction index with Asians & 0.008 & 0.034 & $0.153^{\star \star \star}$ & 0.055 & 0.002 & 0.060 & - & - \\
\hline $\begin{array}{l}\text { Isolation index }{ }^{*} \text { group percent- } \\
\text { age of low-income families }\end{array}$ & 0.000 & 0.000 & 0.000 & 0.001 & 0.001 & 0.000 & 0.002 & 0.003 \\
\hline $\begin{array}{l}\text { Household Factors } \\
\text { (Fixed Effects) }\end{array}$ & & & & & & & & \\
\hline Household income \$0-19,999 & o.c. & o.c. & o.c. & o.c. & o.c. & o.c. & o.c. & o.c. \\
\hline $\begin{array}{l}\text { Household income } \$ 20,000- \\
39,999\end{array}$ & $0.285^{\star \star \star}$ & 0.061 & 0.272 & 0.181 & $0.399^{\star \star}$ & 0.197 & -0.354 & 0.280 \\
\hline $\begin{array}{l}\text { Household income } \$ 40,000- \\
59,999\end{array}$ & $0.772^{\star \star \star}$ & 0.064 & $1.054^{\star \star \star}$ & 0.199 & $1.304^{\star \star \star}$ & 0.244 & 0.172 & 0.324 \\
\hline $\begin{array}{l}\text { Household income } \$ 60,000- \\
74999\end{array}$ & $1.180^{\star \star \star}$ & 0.076 & $1.812^{\star \star \star}$ & 0.358 & $1.332^{\star \star \star}$ & 0.333 & $1.439^{\star \star \star}$ & 0.528 \\
\hline $\begin{array}{l}\text { Household income } \$ 75,000 \text { or } \\
\text { above }\end{array}$ & $1.585^{\star \star \star}$ & 0.072 & $2.497^{\star \star \star}$ & 0.282 & $1.689^{\star \star \star}$ & 0.296 & $0.944^{\star \star \star}$ & 0.326 \\
\hline Education less than high school & o.c. & o.c. & o.c. & o.c. & o.c. & o.c. & o.c. & o.c. \\
\hline $\begin{array}{l}\text { Education high school comple- } \\
\text { tion }\end{array}$ & $0.751^{\star \star \star}$ & 0.103 & $0.547^{\star \star}$ & 0.278 & $1.101^{\star \star \star}$ & 0.266 & 0.450 & 0.469 \\
\hline Education some college & $1.486^{\star \star \star}$ & 0.109 & $1.437^{\star \star \star}$ & 0.269 & $1.918^{\star \star \star}$ & 0.267 & $1.059^{\star \star}$ & 0.460 \\
\hline Education university completion & $1.876^{\star \star \star}$ & 0.109 & $2.228^{\star \star \star}$ & 0.266 & $2.246^{\star \star \star}$ & 0.245 & $1.214^{\star \star \star}$ & 0.450 \\
\hline Location central city & $-0.132^{\star \star}$ & 0.065 & $-0.349^{\star}$ & 0.189 & 0.011 & 0.236 & 0.047 & 0.245 \\
\hline Location suburban & o.c & o.c. & o.c. & o.c. & o.c. & o.c. & o.c. & o.c. \\
\hline $\begin{array}{l}\text { Immigrant household, at least } \\
\text { one spouse immigrant }\end{array}$ & $-0.228^{\star \star}$ & 0.094 & $0.768^{\star \star \star}$ & 0.258 & $-0.512^{\star \star}$ & 0.201 & 0.106 & 0.255 \\
\hline $\begin{array}{l}\text { Immigrant household, both } \\
\text { spouses native-born }\end{array}$ & O.C. & o.c. & o.c. & o.c. & o.c. & o.c. & o.c. & O.c. \\
\hline Random effects for intercept & $0.040^{\star \star \star}$ & & $0.082^{\star \star}$ & & $0.143^{\star \star \star}$ & & 0.053 & \\
\hline
\end{tabular}

Note: ${ }^{* \star *} p<0.01 ;{ }^{* \star} p<0.05 ;{ }^{*} p<0.1$

itan areas is associated with the rate of Internet use among whites. As expected, a higher percentage of white blue-collar workers in metropolitan areas decreases the log-odds of white Internet use by -0.033 .

However, the results show that the log-odds of Internet use among blacks is significantly affected by residential ecology, namely by residential isolation levels and residential interaction levels of metropolitan areas: in other words, by the centripetal and centrifugal dimensions of residential ecology. A higher residential isolation level 
in the metropolitan area increases the log-odds of Internet use among blacks residing there. The corresponding odds is 1.125 (exp (0.118)). The results suggest that blacks residing in these metropolitan areas may find Internet access a means to minimize the detrimental effect of their social isolation, which stems from residential isolation.

As well, more opportunities for residential contact with any other group in the metropolitan area, an indication of the centrifugal dimension of residential ecology, are associated with an increase in the log-odds of Internet use among blacks in those metropolitan areas. The log-odds of Internet use in relation to residential interaction with whites is 0.122 , with Hispanics 0.114 , and with Asians 0.153 . The corresponding odds ratios are $1.13,1.12$, and 1.17 , respectively. The results suggest that the digital divide of blacks is strongly related to both dimensions of the residential ecology of the metropolitan areas where they reside. Yet, at the same time, the results suggest that two seemingly inconsistent ecological processes shape Internet use patterns among blacks.

Finally, differing from the prediction of Hypothesis 2, the results show that a group's spatial isolation and high percentage of low income families in the metropolitan area do not relate to the Internet use of blacks. In fact, the interaction effects do not relate to any group.

Similar to the model for whites but different from that for blacks, the Hispanic model shows that Hispanic Internet use is not affected by residential ecology and other metropolitan characteristics, except for the percentage of residents whose occupation is in management. An increase in the percentage of management workers in metropolitan areas is associated with an increase in the log-odds of Internet use by Hispanics living there.

The Asian model shows that the effects of residential ecology and other metropolitan characteristics on their Internet use are marginal as well. None of the indexes that measure residential ecology were shown to be related to Asian Internet use. Among other metropolitan characteristics, only the percentage of blue-collar workers in the metropolitan area is statistically significant. The log-odds of the percentage of blue-collar workers is -0.139 .

Although this discussion has focused on metropolitan ecological factors, it is worthwhile to mention briefly the effects of household characteristics and residential location. Household characteristics are strongly related to Internet use in all groups. As expected, higher household income or higher level of education of household head is related to the likelihood of more Internet use at home. Finally, residential location (whether it is in a suburban area) is only related to the Internet use of blacks and whites.

In short, the results show unique sets of effects on blacks. Only black Internet use is strongly influenced by both the centripetal and centrifugal dimensions of the residential ecology of the metropolitan areas. However, white, Hispanic, and Asian Internet use is weakly related only to metropolitan occupational distribution. The results also show seemingly inconsistent patterns in the centripetal and centrifugal 
dimensions of residential ecology in black Internet use. We will now address these patterns.

\section{Full HLM Models}

To further explore the effects of ecological factors on Internet use, we ran full hierarchical models that allow factors related to the residential ecology of metropolitan areas to interact with household characteristics. Specifically, we explore how the Internet use of groups is affected by the residential ecology of the metropolitan areas, and their cross-level interaction effects with household income and educational level of household head. We focus on the relationship of the residential ecology of the metropolitan area with respect to household income and household heads' education, because both variables showed consistent and significant effects on Internet use among all groups in our previous analyses.

Among the various indexes to measure residential ecology, we include the isolation index to interact with household characteristics. Since research has emphasized the strong effects of a group's percentage of poor households and its interaction with residential isolation (i.e., the spatial concentration of poverty), which are associated with various detrimental effects on the well-being of residents, we also include these two factors to interact with household characteristics. ${ }^{1}$ In short, we explore how the centripetal dimension of the residential ecology of the metropolitan area indirectly affects the likelihood of Internet use through household income and education of household heads.

For whites, the results show that Internet use is still affected by the percentage of blue-collar workers in the metropolitan area, even when controlling for possible cross-level interaction between metropolitan residential ecology and household characteristics. There is no significant cross-level interaction between metropolitan residential ecology and household characteristics on Internet use by whites. In other words, the direct effects of metropolitan residential ecology or the cross-level interaction effects of the centripetal dimension of residential ecology with household income and household heads' education are not significant.

For blacks, the levels of residential isolation and residential interaction with other groups, i.e., both the centripetal and centrifugal dimensions of residential ecology, have direct and significant effects on Internet use, controlling for cross-level interaction effects and household characteristics. Results suggest that a higher level of residential isolation increases Internet use by blacks: with an additional unit increase in level of residential isolation, the odds of blacks using the Internet at home

1. In another set of analyses not reported here, we include the cross-level interaction effects of interaction indexes with household income and household heads' education. The interaction effects are not significant. 
Table 4. Coefficients of Random Coefficient Model on Internet Use at Home among Whites, Black, Hispanics, and Asians, in Selected 173 MSAs, 2000

\begin{tabular}{|c|c|c|c|c|c|c|c|c|}
\hline & \multicolumn{2}{|c|}{ Whites } & \multicolumn{2}{|c|}{ Blacks } & \multicolumn{2}{|c|}{ Hispanics } & \multicolumn{2}{|c|}{ Asians } \\
\hline & Coefficient & S.E. & Coefficient & S.E. & Coefficient & S.E. & Coefficient & S.E. \\
\hline $\begin{array}{l}\text { Fixed Effects } \\
\text { Intercept }\end{array}$ & $0.171^{\star \star \star}$ & 0.033 & $-1.474^{\star \star \star}$ & 0.119 & $-1.077^{\star \star \star}$ & 0.189 & $0.395^{\star \star}$ & 0.200 \\
\hline $\begin{array}{l}\text { Group percentage of low- } \\
\text { income families }\end{array}$ & -0.040 & 0.045 & -0.050 & 0.034 & $-0.089^{\star}$ & 0.047 & -0.038 & 0.078 \\
\hline $\begin{array}{l}\text { Percentage of management } \\
\text { occupation }\end{array}$ & 0.012 & 0.013 & 0.023 & 0.038 & 0.100 & 0.071 & -0.127 & 0.120 \\
\hline $\begin{array}{l}\text { Percentage of blue-collar oc- } \\
\text { cupation }\end{array}$ & $-0.033^{\star \star \star}$ & 0.007 & -0.023 & 0.023 & -0.008 & 0.034 & $-0.176^{\star \star \star}$ & 0.063 \\
\hline Isolation index & 0.000 & 0.032 & $0.152^{\star \star}$ & 0.060 & $-0.123^{*}$ & 0.068 & 0.296 & 0.380 \\
\hline Isolation index with whites & - & - & $0.153^{\star \star}$ & 0.070 & -0.046 & 0.068 & 0.278 & 0.321 \\
\hline Isolation index with blacks & -0.004 & 0.033 & - & - & -0.020 & 0.064 & 0.282 & 0.310 \\
\hline Isolation index with Hispanics & 0.011 & 0.035 & $0.142^{\star \star}$ & 0.066 & - & - & 0.238 & 0.323 \\
\hline Interaction index with Asians & 0.008 & 0.033 & $0.193^{\star \star \star}$ & 0.067 & -0.008 & 0.069 & - & - \\
\hline $\begin{array}{l}\text { Isolation index }{ }^{*} \text { group percent- } \\
\text { age of low-income families }\end{array}$ & 0.000 & 0.001 & 0.000 & 0.001 & $0.004^{\star \star}$ & 0.002 & -0.003 & 0.011 \\
\hline $\begin{array}{l}\text { Household income \$0-19,999 } \\
\text { Household income } \\
\text { \$20,000-39,999 }\end{array}$ & o.c. & o.c. & o.c. & o.c. & o.c. & o.c. & o.c. & o.c. \\
\hline Intercept & $0.330^{\star \star \star}$ & 0.076 & $0.575^{\star \star}$ & 0.239 & 0.521 & 0.399 & -0.575 & 0.638 \\
\hline $\begin{array}{l}\text { Group percentage of low- } \\
\text { income families }\end{array}$ & 0.081 & 0.116 & -0.011 & 0.081 & 0.275 & 0.262 & -0.350 & 0.492 \\
\hline Isolation index & 0.009 & 0.016 & -0.042 & 0.036 & 0.176 & 0.171 & -1.257 & 1.589 \\
\hline $\begin{array}{l}\text { Isolation index* group percent- } \\
\text { age of low-income families } \\
\text { Household income } \\
\$ 40,000-59,999\end{array}$ & -0.001 & 0.001 & 0.001 & 0.002 & -0.009 & 0.008 & 0.075 & 0.098 \\
\hline Intercept & $0.804^{\star \star \star}$ & 0.076 & $0.575^{\star \star}$ & 0.239 & 0.521 & 0.399 & -0.575 & 0.638 \\
\hline $\begin{array}{l}\text { Group percentage of low- } \\
\text { income families }\end{array}$ & 0.030 & 0.097 & -0.076 & 0.087 & 0.591 & 0.384 & 0.161 & 0.831 \\
\hline Isolation index & -0.002 & 0.014 & -0.037 & 0.040 & 0.344 & 0.236 & -0.108 & 1.291 \\
\hline $\begin{array}{l}\text { Isolation index }{ }^{\star} \text { group percent- } \\
\text { age of low-income families } \\
\text { Household income } \\
\$ 60,000-74999\end{array}$ & 0.000 & 0.000 & 0.001 & 0.002 & -0.017 & 0.011 & -0.012 & 0.090 \\
\hline Intercept & $1.115^{\star \star \star}$ & 0.113 & $1.590^{\star \star \star}$ & 0.494 & 0.690 & 0.659 & 0.267 & 1.523 \\
\hline $\begin{array}{l}\text { Group percentage of low- } \\
\text { income families }\end{array}$ & -0.152 & 0.170 & 0.098 & 0.188 & 0.493 & 0.327 & 1.213 & 1.473 \\
\hline Isolation index & -0.023 & 0.022 & 0.085 & 0.087 & $0.374^{*}$ & 0.211 & 1.663 & 3.519 \\
\hline $\begin{array}{l}\text { Isolation index }{ }^{\star} \text { group percent- } \\
\text { age of low-income families } \\
\text { Household income } \\
\$ 75,000 \text { or above }\end{array}$ & 0.002 & 0.002 & -0.003 & 0.003 & $-0.017^{\star}$ & 0.010 & -0.157 & 0.251 \\
\hline Intercept & $1.701^{\star \star \star}$ & 0.118 & $3.068^{\star \star \star}$ & 0.674 & $1.529^{\star \star \star}$ & 0.498 & -0.865 & 1.897 \\
\hline $\begin{array}{l}\text { Group percentage of low- } \\
\text { income families }\end{array}$ & 0.218 & 0.157 & 0.101 & 0.267 & 0.250 & 0.262 & 1.292 & 1.071 \\
\hline Isolation index & 0.027 & 0.020 & -0.003 & 0.101 & 0.120 & 0.154 & 2.922 & 2.067 \\
\hline $\begin{array}{l}\text { Isolation index }{ }^{*} \text { group percent- } \\
\text { age of low-income families }\end{array}$ & -0.002 & 0.002 & 0.000 & 0.005 & -0.005 & 0.007 & -0.218 & 0.177 \\
\hline
\end{tabular}


Table 4 (cont.).

\begin{tabular}{|c|c|c|c|c|c|c|c|c|}
\hline & \multicolumn{2}{|c|}{ Whites } & \multicolumn{2}{|c|}{ Blacks } & \multicolumn{2}{|c|}{ Hispanics } & \multicolumn{2}{|c|}{ Asians } \\
\hline & Coefficient & S.E. & Coefficient & S.E. & Coefficient & S.E. & Coefficient & S.E. \\
\hline Fixed Effects & & & & & & & & \\
\hline Intercept & $0.171^{\star \star \star}$ & 0.033 & $-1.474^{\star \star \star}$ & 0.119 & $-1.077^{\star \star \star}$ & 0.189 & $0.395^{\star \star}$ & 0.200 \\
\hline $\begin{array}{l}\text { Group percentage of low- } \\
\text { income families }\end{array}$ & -0.040 & 0.045 & -0.050 & 0.034 & $-0.089^{*}$ & 0.047 & -0.038 & 0.078 \\
\hline $\begin{array}{l}\text { Percentage of management } \\
\text { occupation }\end{array}$ & 0.012 & 0.013 & 0.023 & 0.038 & 0.100 & 0.071 & -0.127 & 0.120 \\
\hline $\begin{array}{l}\text { Percentage of blue-collar oc- } \\
\text { cupation }\end{array}$ & $-0.033^{\star \star \star}$ & 0.007 & -0.023 & 0.023 & -0.008 & 0.034 & $-0.176^{\star \star \star}$ & 0.063 \\
\hline Isolation index & 0.000 & 0.032 & $0.152^{\star \star}$ & 0.060 & $-0.123^{\star}$ & 0.068 & 0.296 & 0.380 \\
\hline Isolation index with whites & - & - & $0.153^{\star \star}$ & 0.070 & -0.046 & 0.068 & 0.278 & 0.321 \\
\hline Isolation index with blacks & -0.004 & 0.033 & - & - & -0.020 & 0.064 & 0.282 & 0.310 \\
\hline Isolation index with Hispanics & 0.011 & 0.035 & $0.142^{\star \star}$ & 0.066 & - & - & 0.238 & 0.323 \\
\hline Interaction index with Asians & 0.008 & 0.033 & $0.193^{\star \star \star}$ & 0.067 & -0.008 & 0.069 & - & - \\
\hline $\begin{array}{l}\text { Isolation index }{ }^{\star} \text { group percent- } \\
\text { age of low-income families }\end{array}$ & 0.000 & 0.001 & 0.000 & 0.001 & $0.004^{\star \star}$ & 0.002 & -0.003 & 0.011 \\
\hline $\begin{array}{l}\text { Household income } \$ 0-19,999 \\
\text { Household income } \\
\$ 20,000-39,999\end{array}$ & o.c. & o.c. & o.c. & o.c. & o.c. & o.c. & O.C. & o.c. \\
\hline Intercept & $0.330^{\star \star \star}$ & 0.076 & $0.575^{\star \star}$ & 0.239 & 0.521 & 0.399 & -0.575 & 0.638 \\
\hline $\begin{array}{l}\text { Group percentage of low- } \\
\text { income families }\end{array}$ & 0.081 & 0.116 & -0.011 & 0.081 & 0.275 & 0.262 & -0.350 & 0.492 \\
\hline Isolation index & 0.009 & 0.016 & -0.042 & 0.036 & 0.176 & 0.171 & -1.257 & 1.589 \\
\hline $\begin{array}{l}\text { Isolation index }{ }^{\star} \text { group percent- } \\
\text { age of low-income families } \\
\text { Household income } \\
\$ 40,000-59,999\end{array}$ & -0.001 & 0.001 & 0.001 & 0.002 & -0.009 & 0.008 & 0.075 & 0.098 \\
\hline Intercept & $0.804^{\star \star \star}$ & 0.076 & $0.575^{\star \star}$ & 0.239 & 0.521 & 0.399 & -0.575 & 0.638 \\
\hline $\begin{array}{l}\text { Group percentage of low- } \\
\text { income families }\end{array}$ & 0.030 & 0.097 & -0.076 & 0.087 & 0.591 & 0.384 & 0.161 & 0.831 \\
\hline Isolation index & -0.002 & 0.014 & -0.037 & 0.040 & 0.344 & 0.236 & -0.108 & 1.291 \\
\hline $\begin{array}{l}\text { Isolation index* group percent- } \\
\text { age of low-income families } \\
\text { Household income } \\
\$ 60,000-74999\end{array}$ & 0.000 & 0.000 & 0.001 & 0.002 & -0.017 & 0.011 & -0.012 & 0.090 \\
\hline Intercept & $1.115^{\star \star \star}$ & 0.113 & $1.590^{\star \star \star}$ & 0.494 & 0.690 & 0.659 & 0.267 & 1.523 \\
\hline $\begin{array}{l}\text { Group percentage of low- } \\
\text { income families }\end{array}$ & -0.152 & 0.170 & 0.098 & 0.188 & 0.493 & 0.327 & 1.213 & 1.473 \\
\hline Isolation index & -0.023 & 0.022 & 0.085 & 0.087 & $0.374^{*}$ & 0.211 & 1.663 & 3.519 \\
\hline $\begin{array}{l}\text { Isolation index }{ }^{*} \text { group percent- } \\
\text { age of low-income families } \\
\text { Household income } \\
\$ 75,000 \text { or above }\end{array}$ & 0.002 & 0.002 & -0.003 & 0.003 & $-0.017^{*}$ & 0.010 & -0.157 & 0.251 \\
\hline Intercept & $1.701^{\star \star \star}$ & 0.118 & $3.068^{\star \star \star}$ & 0.674 & $1.529^{\star \star \star}$ & 0.498 & -0.865 & 1.897 \\
\hline $\begin{array}{l}\text { Group percentage of low- } \\
\text { income families }\end{array}$ & 0.218 & 0.157 & 0.101 & 0.267 & 0.250 & 0.262 & 1.292 & 1.071 \\
\hline Isolation index & 0.027 & 0.020 & -0.003 & 0.101 & 0.120 & 0.154 & 2.922 & 2.067 \\
\hline $\begin{array}{l}\text { Isolation index* group percent- } \\
\text { age of low-income families }\end{array}$ & -0.002 & 0.002 & 0.000 & 0.005 & -0.005 & 0.007 & -0.218 & 0.177 \\
\hline Education less than high school & o.c. & o.c. & o.c. & o.c. & o.c. & o.c. & o.c. & o.c. \\
\hline
\end{tabular}


Table 4 (cont.).

\begin{tabular}{|c|c|c|c|c|c|c|c|c|}
\hline \multirow{2}{*}{$\begin{array}{l}\text { Education high school comple- } \\
\text { tion }\end{array}$} & \multicolumn{2}{|c|}{ Whites } & \multicolumn{2}{|c|}{ Blacks } & \multicolumn{2}{|c|}{ Hispanics } & \multicolumn{2}{|c|}{ Asians } \\
\hline & Coefficient & S.E. & Coefficient & S.E. & Coefficient & S.E. & Coefficient & S.E. \\
\hline & $0.836^{\star \star \star}$ & 0174 & O 383 & 316 & 130 & 300 & 01 & 1856 \\
\hline $\begin{array}{l}\text { Group percentage of low- } \\
\text { income families }\end{array}$ & 0.265 & 0.291 & 0.193 & 0.124 & $-0.543^{\star}$ & 0.303 & 0.116 & 0.627 \\
\hline Isolation index & 0.038 & 0.038 & $0.125^{\star}$ & 0.065 & -0.365 & 0.230 & 0.691 & 2.407 \\
\hline $\begin{array}{l}\text { Isolation index }{ }^{*} \text { group percent- } \\
\text { age of low-income families } \\
\text { Education some college }\end{array}$ & -0.004 & 0.004 & $-0.004^{\star}$ & 0.003 & 0.016 & 0.010 & -0.028 & 0.127 \\
\hline Interc & $1.600^{\star \star \star}$ & 0.166 & $1.509^{\star \star \star}$ & 0.357 & $2.174^{\star \star \star}$ & 0.420 & 1.139 & 1.937 \\
\hline $\begin{array}{l}\text { Grou } \\
\text { incon }\end{array}$ & 0.340 & 0.287 & $0.249^{\star \star}$ & 0.123 & $-0.667^{\star}$ & 0.375 & 0.375 & 0.613 \\
\hline Isolation index & 0.049 & 0.039 & $0.115^{\star}$ & 0.063 & -0.422 & 0.262 & 0.563 & 1.850 \\
\hline $\begin{array}{l}\text { Isolation index }{ }^{*} \text { group percent- } \\
\text { age of low-income families } \\
\text { Education university completion }\end{array}$ & -0.004 & 0.004 & -0.004 & 0.002 & 0.018 & 0.011 & -0.033 & 0.112 \\
\hline Intercept & $2.034^{\star \star \star}$ & 0.179 & $2.364^{\star \star \star}$ & 0.340 & $2.833^{\star \star \star}$ & 0.504 & 0.677 & 2.145 \\
\hline $\begin{array}{l}\text { Group percentage of low- } \\
\text { income families }\end{array}$ & 0.340 & 0.290 & 0.077 & 0.128 & $-0.654^{\star \star}$ & 0.281 & 0.197 & 0.712 \\
\hline Isolation index & 0.050 & 0.039 & 0.014 & 0.070 & $-0.436^{\star}$ & 0.243 & 0.847 & 2.579 \\
\hline $\begin{array}{l}\text { Isolation index* group percent- } \\
\text { age of low-income families }\end{array}$ & -0.004 & 0.003 & 0.000 & 0.003 & $0.019^{*}$ & 0.010 & -0.042 & 0.135 \\
\hline Location central city & $-0.128^{\star \star}$ & 0.065 & $-0.404^{\star \star}$ & 0.196 & -0.045 & 0.260 & -0.742 & 0.816 \\
\hline Location suburban & o.c & o.c. & o.c. & o.c. & o.c. & o.c. & o.c. & o.c. \\
\hline $\begin{array}{l}\text { Immigrant household, at least } \\
\text { one spouse immigrant }\end{array}$ & $-0.232^{\star \star}$ & 0.096 & $0.723^{\star \star \star}$ & 0.269 & $-0.399^{\star}$ & 0.227 & 0.258 & 0.714 \\
\hline $\begin{array}{l}\text { Immigrant household, both } \\
\text { spouses native-born }\end{array}$ & o.c. & o.c. & o.c. & o.c. & o.c. & o.c. & o.c. & o.c. \\
\hline Random effect for intercept & $0.041^{\star * *}$ & & $0.087^{\star \star}$ & & $0.142^{\star \star \star}$ & & 0.159 & \\
\hline
\end{tabular}

Note: ${ }^{* \star} p<0.01 ;{ }^{* \star} p<0.05 ;{ }^{*} p<0.1$

will be $1.164(\exp (0.152))$ higher. Thus, blacks may use the Internet to break the social isolation caused by physical concentration, and that they sustain interaction and obtain information through the Internet.

At the same time, the results suggest that a higher level of residential interaction with any group considerably increases the log-odds of Internet use among blacks. A unit of increase in residential interaction with whites, Hispanics, and Asians will raise the odds of black Internet use 1.17, 1.15, and 1.21 times, respectively. In fact, these effects are stronger than the effects of the same set of factors on Internet use without controlling for cross-level interaction. The results offer strong support of the effects of residential ecology on blacks' adaptation to Internet use. However, the interaction effect of the residential isolation and percentage of low income families is no longer significant.

The results show the cross-level interaction effects of the centripetal dimension of residential ecology with the education level of household heads affect black Internet use as well. The results explain the seemingly inconsistent results of the positive effects of residential interaction and residential isolation levels on Internet use among 
blacks. The positive effects of the residential isolation index are especially important to black household heads with higher levels of education. Black household heads with high school completion and some college education are more likely to use the Internet, perhaps because they realize the important implications of Internet use that go beyond the constraints of and minimize the possible negative influences of residing in cities with high levels of residential isolation or high spatial concentration of poverty.

For Hispanics, the full HLM model suggests that, among all metropolitan characteristics, only the percentage of Hispanic low-income households, the Hispanic residential isolation level, and the spatial concentration of poverty in the metropolitan area remain significant, allowing for cross-level interaction effects between ecological and household characteristics. The effect of spatial concentration of poverty is minimal. The log-odds of the estimated effect is 0.004 , with the odds close to independent between this factor and Hispanic Internet use. Although the interaction effect of the residential isolation and larger percentage of low-income families becomes significant, it remains small.

The model also reveals that the cross-level interaction effects of residential isolation with medium-high income groups are significantly related to the likelihood of Hispanic Internet use. Hispanic household heads with medium-high income (i.e., household income between $\$ 60,000-74,999)$ living in metropolitan areas with higher residential isolation levels are more likely to use the Internet at home. However, the Internet use of Hispanics is reduced when the same group is living in metropolitan areas with high levels of poverty concentration (i.e., high level of residential isolation and high percentage of poor Hispanic households in the metropolitan area).

Hispanic Internet use at home is further affected by the cross-level interaction of residential isolation and spatial concentration of poverty with individuals' education levels. A higher percentage of poor Hispanic households in the metropolitan area is consistently associated with lower log-odds of Internet use among Hispanic household heads who have completed high school or university living there. The isolation index is only, albeit negatively and strongly, associated with Internet use among those households with heads who have completed university. In short, the results show that, in the metropolitan areas, a higher percentage of poor Hispanic households or a higher level of residential isolation lowers the likelihood of Internet use at home among those households whose heads have higher education.

Finally, the Asian full HLM model shows that residential ecology, other metropolitan characteristics, and household characteristics have limited direct effects on Internet use, allowing for cross-level interaction between residential ecology and household characteristics. Nor do the cross-level interaction effects between residential ecology and household characteristics show a significant effect on Internet use.

\section{Conclusion}

It perhaps goes without saying that Internet use provides a good vantage point from which to explore social change in modern societies. In fact, the increasing signifi- 
cance of the Internet as a shaping force in our social, economic, and political activities has motivated studies probing the patterns of Internet use, most of which show a distinct digital divide among racial groups. However, most of these studies focus on individual socioeconomic factors to explain this divide. Our paper extends the study of residential ecology and the Internet by suggesting that the residential ecology of the metropolitan areas, in addition to household socioeconomic factors, should be considered in understanding Internet use. We argue that centripetal dimension of residential ecology, represented by residential isolation and the spatial concentration of the poor, and the centrifugal dimension of residential ecology, reflected by residential interaction of groups, are important in understanding the digital divide between racial groups - in this case, black, Hispanic, Asian, and white.

Based on the August 2000 Current Population Survey Computer and Internet Use Supplement, our results suggest that blacks are affected positively by the direct effects of the centripetal and centrifugal dimensions of residential ecology. A higher level of residential isolation and a higher level of residential interaction with other groups in the metropolitan areas are directly and positively related to the likelihood of Internet use among blacks living there. In other words, no matter whether blacks experience a higher level of residential isolation or a higher level of residential interaction, both can positively affect their Internet use.

The seemingly inconsistent findings of blacks' Internet use in relation to residential ecology are that their Internet use is strongly related to the cross-level interaction effects of the centripetal dimension of residential ecology with household heads' education levels. As suggested by Hypothesis 1, the cross-level interaction of a higher level of residential isolation or a higher percentage of blacks in metropolitan areas, with black households whose heads have completed college, increases the likelihood of black Internet use. In other words, not all black household heads residing in cities with high residential isolation have a higher likelihood of using Internet. Only when those black household heads have higher educational levels are they more likely to adopt the Internet. The results may reflect that black households with higher educational characteristics residing in metropolitan areas with higher levels of residential isolation realize the importance of Internet as a means to escape their social isolation and to obtain information. However, given that blacks experience a high level of residential isolation in most cities, and that they also have lower educational levels than other groups, these findings may not apply to most blacks living in a high level of residential isolation.

The results show support of the second hypothesis only pertinent to Hispanic Internet use. There is a support of the interaction effect of residential isolation and percentage of low income families when cross-level effects are included in the model. Its cross-level interaction effects with household income and education of household heads are related to Internet use. In other words, a higher residential isolation level or a higher percentage of Hispanic poor reduces the effects of household heads' educational levels on the likelihood of Internet use. The centripetal residential 
ecology reduces the likelihood of Hispanic Internet use directly, as well as indirectly, through household socioeconomic resources. Though Hispanics have a higher average household income than blacks, their residential isolation levels have increased over the decades. As a result, the residential isolation's suppression effect on the relationship between household socioeconomic characteristics and likelihood of Internet use considerably weakens the relatively advantaged economic position of Hispanic households. Finally, the results, as suggested in the third hypothesis, show that the likelihood of Internet use is only and strongly related to black residential interaction levels. Having higher residential interaction with any group, blacks increase the likelihood of Internet use.

By incorporating residential ecology into the study, we have demonstrated the value of going beyond household socioeconomic characteristics to explain Internet use, especially for blacks. However, it is worthwhile to mention that the likelihood of Internet use by whites and Asians is not related to residential ecology. The disconnectedness of residential ecology from Internet use allows them to take full advantage of their higher level of household resources.

In conclusion, our paper shows that residential ecology is important to understanding Internet use of minority groups, especially blacks and Asians. It further shows that certain residential ecologies can have positive effects on the Internet use of groups with generally lower usage rates. Even in segregated neighborhoods, the promotion of Internet use can help to "bridge" social isolation for residents with higher education and narrow the racial digital divide. However, the study leaves open the door for future research. Although our research shows the importance of residential ecology in understanding the Internet use of blacks and Hispanics, it also shows that whites and Asians are not affected significantly by these factors. Future research should explore why this is so.

\section{References}

Alba, Richard D., Nancy A. Denton, Shu-Yin Leung, John R. Logan. 1995. "Neighborhood Change under Conditions of Mass Immigration: The New York City Region, 1970-1990.” International Migration Review 29:625-56.

Alvarez, Anthony Steven. 2003. "Behavioral and Environmental Correlates of Digital Inequality." IT \& Society 1:97-140.

Anderson, Elijah. 1990. Streetwise: Race, Class, and Change in an Urban Community. Chicago: University of Chicago Press.

Axinn, William and Scott T. Yabiku. 2001. "Social Change, the Social Organization of Families, and Fertility Limitation.” American Journal of Sociology 106:1219-61.

Baybeck, Brady and Robert Huckfeldt. 2002. "Urban Contexts, Spatially Dispersed Networks, and the Diffusion of Political Information.” Political Geography 21:195- 220. 
Bell, Wendall. 1954. "A Probability Model for the Measurement of Ecological Segregation.” Social Forces 32(May):357-364.

Burgess, Ernest. 1968. “The Growth of the City: An Introduction to a Research Project.” Pp. 47-62 in The City, edited by Robert E. Park, Ernest W. Burgess, and Roderick D. McKenzie. Chicago: University of Chicago Press.

Castells, Manuel. 1989. The Informational City: Information, Technology, Economic Restructuring, and the Urban-Regional Process. New York: Blackwell.

2000. "Grassrooting the Space of Flows." Pp.18-30 in Cities in the Telecommunications Age: The Fracturing of Geographies, edited by James O. Wheeler, Yuko Aoyama, and Barney Warf. New York: Routledge Press.

Clark, William A.V. 1986. "Residential Segregation in American Cities: A Review and Interpretation." Population Research and Policy Review 5:95-127.

DeNavas-Watt, Carnen, Robert W. Cleveland, and Marc J. Roemer. 2001. Money Income in the United States: 2000. US Census Bureau Series, Current Population Reports pp. 60-213. Washington, DC: US Government Printing Office.

DiMaggio, Paul and Joseph Cohen. 2005. "Information Inequality and Network Externalities: A Comparative Study of the Diffusion of Television and the Internet.” Pp. 227-267 in The Economic Sociology of Capitalism, edited by Victor Nee and Richard Swedberg. Princeton, NJ: Princeton University Press.

DiMaggio, Paul, Eszter Hargittai, W. Russell Neuman, and John P. Robinson. 2001. "Social Implications of the Internet." Annual Review of Sociology 27:307-336.

Dryburgh, Heather. 2001. "Changing Our Ways: Why and How Canadians Use the Internet." Statistics Canada, Catalogue Number 56F0006XIE2000001. (http://www.statcan.ca/bsolc/english/ bsolc? catno $=56 \mathrm{~F} 0006 \mathrm{X})$

Economic and Statistics Administration and National Telecommunications and Information Administration. 2002. A Nation Online: How Americans are Expanding Their Use of the Internet. Washington, DC: US Department of Commerce. http://www.ntia.doc.gov/ntiahome/dn/anationonline2.pdf.

Firey, Walter. 1945. "Sentiment and Symbolism as Ecological Variables." American Sociological Review 10:140-148.

Fischer, Claude S., Gretchen Stockmayer, Jon Stiles, and Michael Hout. 2004. "Distinguishing the Geographic Levels and Social Dimensions of U.S. Metropolitan Segregation, 1960-2000." Demography 41:37-59.

Fong, Eric, Barry Wellman, Melissa Kew, and Rima Wilkes. 2001. "Correlates of the Digital Divide: Individual, Household and Spatial Variation.” Report to Office of Learning Technologies, Human Resources Development Canada.

Gerber, Theodore P. and Michael Hout. 1998. "More Shock than Therapy: Market Transition, Employment, and Income in Russia, 1991-1995." American Journal of Sociology 104:1-50.

Hampton, Keith and Barry Wellman. 2003. "Neighboring in Netville: How the Internet Supports Community and Social Capital in a Wired Suburb." City and Community 2:277-311.

Haveman, Robert, Barbara Wolfe, and Kathryn Wilson. 1997. "Childhood Poverty and Adolescent Schooling and Fertility Outcomes: Reduced-Form and Structural Estimates." Pp 419-460 in Consequences of Growing Up Poor, edited by Greg J. Duncan and Jeanne Brooks-Gunn. New York: Russell Sage Foundation. 
Hawley, Amos H. 1986. Human Ecology: A Theoretical Essay. Chicago: University of Chicago Press.

Hoffman, Donna L. and Thomas P. Novak. 1998. "Bridging the Racial Divide on the Internet." Science 280(April 17):390-391.

Hogan, Dennis P., and Evelyn M. Kitagawa. 1985. "The Impact of Social Status, Family Structure, and Neighborhood on the Fertility of Black Adolescents." American Journal of Sociology 19:825-855.

Iceland, John. 2004. "Beyond Black and White - Metropolitan Residential Segregation in Multi-Ethnic America." Social Science Research 33:248-71.

Iceland, John, Daniel H. Weinberg, and Erika Steinmetz. 2002. Racial and Ethnic Residential Segregation in the United States: 1980-2000. US Census Bureau Series CENSR-3. Washington, DC: US Government Printing Office.

Jackson, Linda A., Gretchen Barbatsis, Alexander von Eye, Frank Biocca, Yong Zhao, and Hiram Fitzgeral. "Internet Use in Low-Income Families: Implications for the Digital Divide." IT \& Society $1: 141-165$.

Kominski, Robert and Eric Newburger. 1999. Access Denied: Changes in Computer Ownership and Use: 1984-1997. Paper presented at the American Sociological Association, Chicago.

Kuhn, Peter and Mikal Skuterud. 2000. "Job Search Methods: Internet versus Traditional." Monthly Labor Review October: 3-11.

Lieberson, Stanley. 1980. Piece of the Pie: Blacks and White Immigrants Since 1880. Berkeley: University of California Press.

Lieberson, Stanley and Donna Carter. 1982. "A Model for Inferring the Voluntary and Involuntary Causes of Residential Segregation.” Demography 19:511-526.

Lin Nan. 2001. Social Capital: A Theory of Social Structure and Action. New York: Cambridge University Press

Logan, John R., Brian J. Stults, and Reynolds Farley. 2004. "Segregation of Minorities in the Metropolis: Two Decades of Change." Demography 41:1-22.

Massey, Douglas S. 1985. "Ethnic Residential Segregation: A Theoretical Synthesis and Empirical Review." Sociology and Social Research 69:315-350.

Massey, Douglas S., Gretchen A. Condran, and Nancy A. Denton. 1987. "The Effect of Residential on Black Social and Economic Well-Being." Social Forces 66:29-56.

Massey, Douglas S. and Nancy A. Denton. 1987. "Trends in the Residential Segregation of Blacks, Hispanics, and Asians." American Sociological Review 52:802-25.

1993. American Apartheid: Segregation and the Making of the Underclass. Cambridge, MA: Harvard University Press.

Massey, Douglas S. and Mitchell L. Eggers. 1990. "The Ecology of Inequality: Minorities and the Concentration of Poverty, 1970-1980.” American Journal of Sociology 95:1153-1188.

Massey, Douglas S. and Eric Fong. 1990. "Segregation and Neighborhood Quality: Blacks, Hispanics, and Asians in the San Francisco Metropolitan Areas." Social Forces 69:15-32.

Massey, Douglas S. and Kumiko Shibuya. 1995. "Unravelling the Tangle of Pathology: The Effect of Spatially Concentrated Joblessness on the Well-being of African Americans." Social Science Research 24:352-66. 
Mossberger, Karen, Carline J. Tolbert, and Mary Stansbury. 2003. Virtual Inequality: Beyond the Digital Divide. Washington, DC: Georgetown University Press.

Mossberger, Karen, Caroline J. Tolbert, and Michele Gilbert. 2006. "Race, Place, and Information Technology." Urban Affairs Review 41(5):583-620.

Mueller, Milton and Jorge Reina Schement. 1996. "Universal Service from the Bottom Up: A Study of Telephone Penetration in Camden, New Jersey.” Information Society 12:273-292.

Nee, Victor. 1996. "The Emergence of a Market Society: Changing Mechanisms of Stratification in China." American Journal of Sociology 100:908-949.

Neuman, W. Russell, Richard Jay Solomon, Lee W. McKnight. 1998. The Gordian Knot: Political Gridlock on the Information Highway. Cambridge, MA: MIT Press.

Park, Robert. 1936. "Human Ecology” American Journal of Sociology 42:1-15.

Pew Internet and American Life Project. 2000. African Americans and the Internet. http://www.pewInternet.org.

Polednak, Anthony P. 1997. Segregation, Poverty, and Mortality in Urban African Americans. New York: Oxford University Press.

Portes, Alejandro and Julia Sensenbrenner. 1993. "Embeddedness and Immigration: Notes on the Social Determinants of Economic Action." American Journal of Sociology 98:1320-1350.

Powers, Daniel A. and Christopher G. Ellison. 1995. "Interracial Contact and Black Racial Attitudes: The Contact Hypothesis and Selectivity Bias." Social Forces 74:205-226.

Prieger, James E. 2003. "The Supply Side of the Digital Divide: Is There Equal Availability in the Broadband Internet Access Market?" Economic Inquiry 41:346-363.

Raudenbush, Stephen W. and Anthony S. Bryk. 2002. Hierarchical Linear Models: Applications and Data Analysis Methods. Thousand Oaks, CA: Sage Publications.

Robinson John P. and Meyer Kestnbaum. 1999. The personal computer, culture and other uses of free time. Social Science Computer Review 17:209-216.

Sampson Robert J., Jeffrey Morenoff, and Felton Earls. 1999. "Beyond Social Capital: Spatial Dynamics of Collective Efficacy for Children.” American Sociological Review 64:633-660.

Sampson, Robert J., Jeffrey D. Morenoff, and Thomas Gannon-Rowley. 2002. "Assessing 'Neighborhood Effects': Social Processes and New Directions in Research.” Annual Review of Sociology 28:443-478.

Servon, Lisa. 2002. Bridging the Digital Divide: Technology, Community, and Public Policy. Malden, MA: Blackwell.

Sigelman, Lee and Susan Welch. 1993. "The Contact Hypothesis Revisited: Black-White Interaction and Positive Racial Attitudes.” Social Forces 71:781-795.

Spooner, Tom and Lee Rainie. 2004. “African-Americans and the Internet.” Pew Internet \& American Life Project (http://www.pewinternet.org).

2001. "Hispanics and the Internet." Pew Internet \& American Life Project (http://www.pewinternet.org)

Stark, David and Laszlo Bruszt. 1998. Postsocialist Pathways: Transforming Politics and Property in East Central Europe. New York: Cambridge University Press. 
Stier, Haya and Marta Tienda. 2001. The Color of Opportunity: Pathways to Family, Welfare, and Work. Chicago: University of Chicago Press.

Welch, Susan, Lee Sigelman, and Michael Combs. 2001. Race and Place: Race Relations in an American City. New York: Cambridge University Press.

Wellman, Barry, Salaff Janet, Dimitrina Dimitrova, Laura Garton, Milena Gulia, and Caroline Haythornwaite. 1996. "Computer Networks as Social Networks: Collaborative Work, Telework, and Virtual Community." Annual Review of Sociology 22:213-38.

White, Michael J., Ann E. Biddlecom, and Shenyeng Guo. 1993. "Immigration, Naturalization, and Residential Assimilation Among Asian Americans in 1980.” Social Forces 72:93-117.

Wilkes, Rima and John Iceland. 2004. "Hypersegregation in the Twenty-First Century.” Demography 41:23-36

Wilson, William Julius. 1999. The Bridge over the Racial Divide: Rising Inequality and Coalition Politics. Los Angeles: University of California Press.

1987. The Truly Disadvantaged: The Inner City, the Underclass, and Public Policy. Chicago: University of Chicago Press

1996. When Works Disappear: The World of the New Urban Poor. New York: Random House.

Xiaobo Zhang, Shenggen Fan, and Ximing Cai. 2002. "The Path of Technology Diffusion: Which Neighbors to Learn From?" Contemporary Economic Policy 20(4):470-478.

Zhou, Min. 1997. "Segmented Assimilation: Issues, Controversies, and Recent Research on the New Second Generation.” International Migration Review 31(4):825-858.

Zook, Matthew A. 2005. Geography of the Internet Industry: Virtual Capital, Dot-coms, and Local Knowledge. Oxford: Blackwell. 
